\title{
PENINGKATAN DAYA DUKUNG PONDASI PADA TANAH LEMPUNG DENGAN PERKUATAN KOLOM TANAH
}

\author{
Ratna Dewi $^{* 1)}$, Hanafiah ${ }^{2)}$ dan Ridho Ustadi ${ }^{3)}$ \\ ${ }^{1,2,3)}$ Jurusan Teknik Sipil FT UNSRI, Jl. Raya Prabumulih - Km 32 Indralaya, Ogan Ilir, Sumsel
}

\begin{abstract}
One of the problematic soils for construction if the soil is used as a foundation for a construction is clay soil which has relatively low shear strength and bearing capacity. Therefore, it needs an improvement effort to increase the strength of the clay soil. The reinforcement soil column is an alternative effort to improve the soil. This paper presents the results of laboratory-scale experimental on the reinforcement modelling of clay soil columns mixed with $6 \%$ rice husk ash (RHA). Modelling was carried out with 6 variations of column groups with constant column length of $67 \mathrm{~cm}$. The first three variations are the variation in the distance between columns $(\mathrm{s} / \mathrm{d})$ with a fixed diameter of $8 \mathrm{~cm}$. The other three variations are column diameter variations with a fixed s/d ratio. The results showed that the larger the distance between the columns, the smaller the bearing capacity of the soil foundation. If the s/d ratio is constant, it is found that the larger the column diameter, the greater the bearing capacity of the soil foundation. The maximum ultimate bearing capacity of the soil is achieved in variations with a column diameter of $12 \mathrm{~cm}$ and a distance between columns of $30 \mathrm{~cm}$ $(\mathrm{s} / \mathrm{d}=2.5)$ with a value of $39.56 \mathrm{kPa}$. This bearing capacity provides a BCR value of $3.75 \%$ or almost 4 times the bearing capacity of the unreinforced foundation.
\end{abstract}

Key Words: bearing capacity, clay soil, RHA, soil column.

\section{PENDAHULUAN}

Tanah merupakan hal yang sangat penting pada sebuah konstruksi, karena berhasil atau tidaknya suatu proyek konstruksi sangat tergantung dengan kondisi tanah pendukungnya. Kondisi tanah yang bermasalah seperti kuat geser rendah menyebabkan daya dukung yang rendah, tingkat pengembangan dan kompresibilitas yang tinggi. Hal ini dapat menyebabkan keruntuhan tanah jika konstruksi dibangun di atasnya. Oleh karena itu, tanah memegang peranan penting untuk kekuatan struktur bawah konstruksi. Salah satu jenis tanah yang harus diperhatikan dalam sebuah kontruksi yaitu tanah lempung.

Tanah lempung terbentuk dari pembusukan kimiawi unsur-unsur penyusun batuan, dan terdiri dari agregat partikel yang memiliki ukuran mikro dan submikroskopik. Tanah lempung dalam kondisi kadar air tinggi (basah) dapat bersifat lengket karena kohesi, memiliki tekstur keras dalam kondisi kering, bersifat plastis ketika dalam keadaan tidak kering dan tidak basah, dan memiliki permeabilitas yang rendah (Terzaghi \& Ralph, 1987). Tanah lempung yang lunak memiliki sifat kuat geser dan daya dukung yang rendah. akan menjadi kendala dan masalah jika langsung digunakan sebagai tanah dasar konstruksi.
Oleh karena itu, perlu dilakukan perbaikan pada tanah lempung sebelum digunakan sebagai tanah dasar. Usaha perbaikan atau stabilisasi tanah lempung bermasalah telah banyak dilakukan, yang bertujuan untuk meningkatkan daya dukung tanah, menurunkan sifat kompresibilitas dan mengurangi sifat yang mudah dipengaruhi air.

Penggunaan kapur dan semen pada tanah lempung mampu meningkatkan kuat geser dan mampu memberikan ketahanan campuran terhadap perubahan iklim (Puppala \& Pedarla, 2017). Metode lain yang dapat memperbaiki tanah lempung yaitu dengan metode vibrocompacted stone column untuk peningkatan modulus Young tanah lempung lunak (Guetif dkk., 2007), metode electro-osmosis (Estabragh dkk., 2014), penggunaan CFG pile sebagai metode perbaikan tanah lunak diatas Highgrade highway di Guandong, China (He \& Liu, 2020). Sistem prefabricated vertical drains (PVDs) yang dikombinasikan dengan surcharge dan vacuum preloading merupakan metode efektif untuk mempercepat konsolidasi tanah lempung lunak (Basha dkk., 2014), serta metode lainnya seperti Deep Soil Mixing (DSM) atau kolom tanah campuran.

Dehghanbanadaki dkk. (2013) melakukan penelitian mengenai DSM (pemasangan, sifat fisis tanah dan tipe bahan binder soil column yang 
bertujuan untuk meningkatkan daya dukung dan mengurangi penurunan tanah lempung lunak. Tipe binder yang digunakan antara lain, kapur, semen dan abu sekam padi / Rice Husk Ash (RHA). Penggunaan abu sekam padi untuk campuran DSM/kolom tanah lempung terbukti dapat meingkatkan daya dukung pondasi dangkal pada tanah gambut (Dewi dkk., 2019).

Menurut (Abdurrozak \& Mufti, 2017), abu sekam padi merupakan hasil limbah pembakaran dari sekam padi. Abu sekam padi ini memiliki kanduangan $\mathrm{SiO}_{2}$ yang tinggi, dimana kandungan kimia ini memiliki sifat pozzolan yang mudah mengeras sehingga dapat digunakan sebagai bahan stabilisasi tanah.

\section{METODOLOGI}

Paper ini menyajikan hasil pengujian pembebanan pondasi dangkal tanpa perkuatan dan dengan perkuatan kolom tanah lempung $+6 \%$ RHA. Kolom tanah yang diaplikasikan adalah kolom kelompok dengan jumlah 4 kolom (2x2).

Pengunaan komposisi tanah lempung yang dicampur RHA pada kolom berdasarkan hasil pengujian stabilisasi tanah lempung, dimana komposisi optimal untuk nilai qu (UCS) maksimal adalah tanah lempung + 6\%RHA (Oktavia dkk., 2019).

\section{Tanah Lempung dan RHA.}

Tanah lempung (disturbed) sebagai media tanah yang diperbaiki dan sebagai tanah pencampur RHA diambil dari daerah Pedamaran Kabupaten Ogan Komering Ilir Sumatera Selatan. Jenis tanah lempung ini diklasifikasikan sebagai $\mathrm{CH}$ Clay / lempung dengan high plasticity berdasarkan USCS clasification dan dalam kelompok A-7-5 berdasarkan AASTHO.

Sampel RHA (Gambar 1) diambil dari sisa hasil pembakaran sekam padi di daerah Lahat, Sumatera Selatan, dimana kandungan silica (sebagai bahan utama pozzolan) dari bahan tersebut sebesar 39,16\% (Tabel 1).

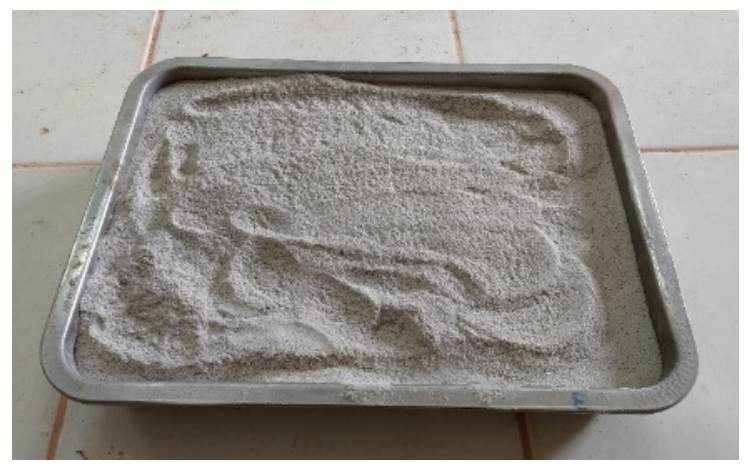

Gambar 1. Abu Sekam Padi (RHA)
Tabel 1. Unsur kimiawi RHA

\begin{tabular}{ccc}
\hline Unsur & Simbol & $\begin{array}{c}\text { Persentase } \\
(\%)\end{array}$ \\
\hline Oxygen & $\mathrm{O}$ & 53.9 \\
Silicon & $\mathrm{Si}$ & 39.16 \\
Carbon & $\mathrm{C}$ & 3.16 \\
Kalium & $\mathrm{K}$ & 1.61 \\
Unsur kimiawi lainnya & & 2.17 \\
\hline
\end{tabular}

Sifat fisis dan mekanis untuk campuran tanah lempung dengan 6\%RHA, yang didapat dari hasil penelitian sebelumnya, dapat dilihat pada Tabel 2

Tabel 2. Sifat fisis dan mekanis campuran tanah lempung $+6 \%$ RHA

\begin{tabular}{lll}
\hline No. & Karakteristik bahan campuran & Nilai \\
\hline 1. & Spesific Gravity (Gs) & 2.55 \\
2. & Liquid Limit (LL) & $94.50 \%$ \\
3. & Plastic Limit (PL) & $52.12 \%$ \\
4. & Indeks Plastisitas (PI) & $42.38 \%$ \\
5. & Kadar Air Optimum $\left(\omega_{\mathrm{opt}}\right)$ & $37.10 \%$ \\
6. & Dry Density Maksimum $\left(\gamma_{\mathrm{d} \text { maks }}\right)$ & $1.29 \mathrm{gr} / \mathrm{cm}^{3}$ \\
7. & qu dari hasil UCS (Masa perawatan & $1.05 \mathrm{~kg} / \mathrm{cm}^{2}$ \\
& 7 hari) \\
\hline sumber: Oktavia dkk., 2019).
\end{tabular}

Tabel 2 menunjukkan bahwa Unconfined Compressive Strength (qu) tanah setelah dicampur dengan RHA memiliki besaran nilai yang cukup tinggi, sehingga memungkinkan untuk digunakan sebagai kolom perkuatan tanah.

\section{Pemodelan Benda Uji}

Variasi pemodelan kolom tanah lempung $+6 \%$ RHA yang diaplikasikan disajikan pada Tabel 3, dimana dilakukan dengan variasi pemodelan.

Tabel 3. Variasi pemodelan kolom tanah campuran

\begin{tabular}{ccccc}
\hline No & $\mathbf{d ~ ( c m ) ~}$ & $\mathbf{L ~ ( c m ) ~}$ & $\mathbf{s}(\mathbf{c m})$ & $\mathbf{( s / d )}$ \\
\hline 1 & 8 & 67 & 22 & 2,75 \\
2 & 8 & 67 & 24 & 3 \\
3 & 8 & 67 & 28 & 3,5 \\
4 & 8 & 67 & 20 & 2,5 \\
5 & 10 & 67 & 25 & 2,5 \\
6 & 12 & 67 & 30 & 2,5 \\
\hline
\end{tabular}

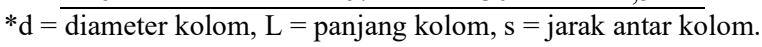

Pemodelan perkuatan kolom campuran tanah lempung dan RHA yang diuji adalah kolom kelompok (2x2) dengan pondasi dangkal berukuran $30 \mathrm{~cm} \times 30 \mathrm{~cm}$. Boks uji yang digunakan berdimensi $2 \mathrm{~m} \times 1 \mathrm{~m} \times 1,4 \mathrm{~m}$ yang dilapisi dengan plastik supaya kedap air dan menjaga kadar air tanah lempung tetap terjaga. Setelah tanah lempung dimasukkan dalam boks, tanah dibiarkan selama 1 hari dalam kondisi tidak terjadi penguapan kadar air dan diuji vane shear untuk memastikan kadar air dan kuat geser lempung seragam pada setiap variasi uji.

Kolom tanah campuran diaplikasikan dalam tanah lempung dengan mengikuti cara pelaksanaan 
Cantilever $\mid$ Volume: 9 Nomor: 2 Oktober 2020 ISSN: 1907-4247 (Print) $\mid$ ISSN: 2477-4863 (Online) $\mid$ Website: http://cantilever.id Ratna Dewi, dkk. | Peningkatan Daya Dukung Pondasi pada Tanah Lempung dengan Perkuatan Kolom Tanah

di lapangan, yaitu dengan menggunakan alat bor.

Bor tanah lempung dalam bak uji sesuai dengan kedalaman yang diencanakan. Setelah selesai pengeboran, dimasukkan RHA melalui pipa baja yang ditancapkan ke dalam tanah yang sudah di bor. Kemudian dilakukan pengadukan dengan menggunakan alat pengaduk supaya tanah dan RHA menyatu. Setelah kolom terpasang dan dilakukan masa perawatan selama 4 hari, kemudian dilakukan penyetelan alat dongkrak, LVDT dan data logger. Sketsa pengujian pembebanan kolom kelompok diilustrasikan pada Gambar 2.

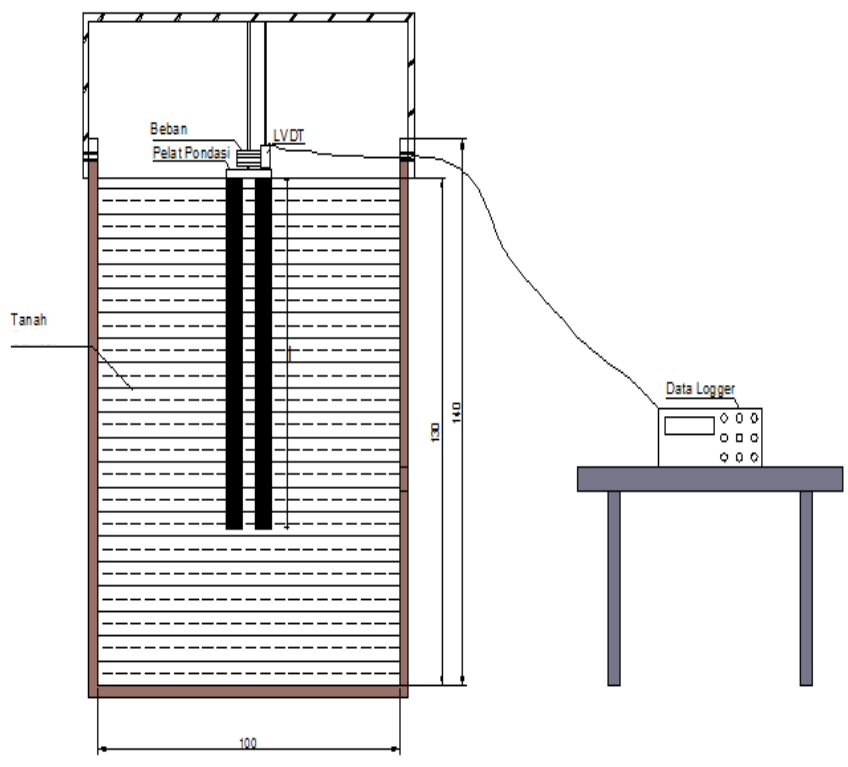

Gambar 2. Sketsa pengujian untuk kolom kelompok

Konfigurasi variasi kolom kelompok dan tampak atas dari kolom yang telah terpasang/tertanam di dalam tanah lempung dapat dilihat pada Gambar 3 dan 4 .
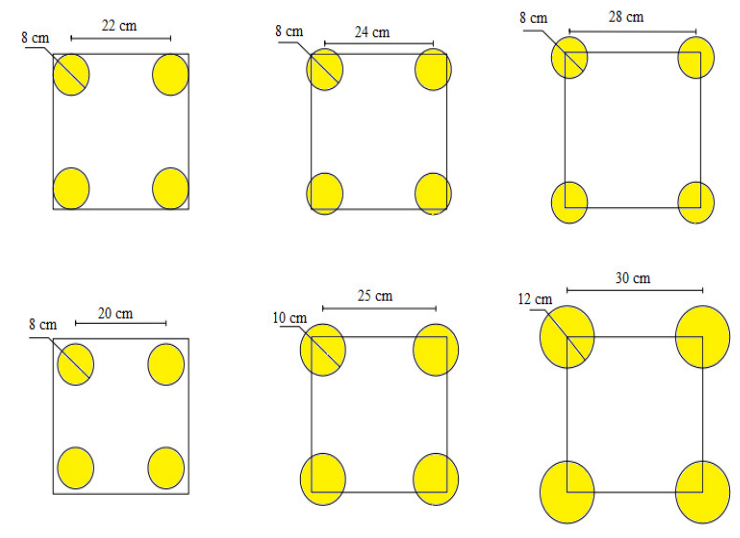

Gambar 3. Ilustrasi variasi konfigurasi kolom kelompok

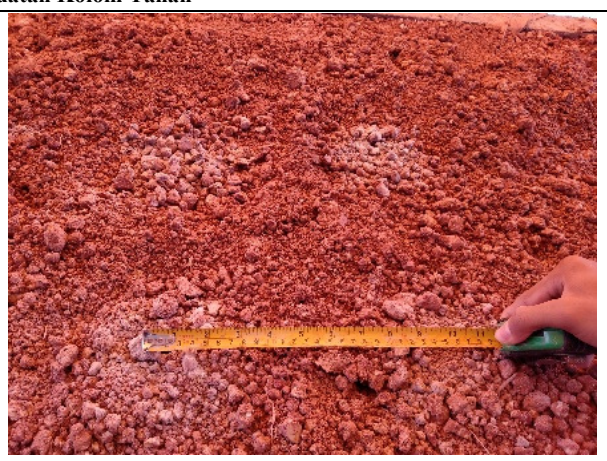

Gambar 4. Foto tampak atas kolom tanah yang telah tertanam dalam tanah lempung

Pengujian pembebanan menggunakan prosedur ASTM D-1143 yang termasuk dalam jenis uji pembebanan Quick Maintained Load Test (QML) dengan peningkatan beban dilakukan secara bertahap setiap 5\% dari beban rencana hingga keruntuhan beban tercapai.

\section{HASIL DAN PEMBAHASAN}

Sebelum dilakukan pengujian pembebaan pada tanah baik sebelum diberi perkuatan kolom ataupun setalah diberi perkuatan, tanah lempung diuji vane shear terlebih dahulu untuk memastikan keseragaman kondisi tanah lempung. Pada pengujian ini didapatkan nilai torsi yang digunakan untuk menentukan nilai kohesi $(\mathrm{Cu})$. Nilai torsi yang didapat digunakan sebagai acuan dalam pembentukan tanah lempung dalam bak sehingga didapatkan kondisi tanah lempung yang sama pada setiap pengujian pembebanan. Hasil pengujian tanah asli/tanah lempung mendapatkan nilai $\mathrm{Cu}$ sebesar $13,63 \mathrm{kPa}$. Sedangkan nilai kohesi dari pengujian vane shear pada kolom yang telah dibuat/tertanam pada tanah sebesar $25,2 \mathrm{kPa}$. Hal ini menunjukan kondisi tanah pada kolom terjadi peningkatan nilai kohesi $2 \mathrm{x}$ lipat dari tanah tanpa kolom.

Hasil pengujian pembebanan untuk pondasi tanpa ada perkuatan disajikan pada grafik hubungan penurunan dan beban (Gambar 5), dimana dari grafik ini didapat kapasitas dukung ultimit pondasi tanpa perkuatan.

Interpretasi data dari grafik hubungan antara penurunan dan beban adalah dengan mengunakan metode tangen. Dari grafik diatas diperoleh nilai beban ultimit sebesar 0,89 $\mathrm{kN}$, sehingga kapasitas/daya dukung ultimit pondasi pada tanah lempung sebelum diberi perkuatan sebesar 10.53 $\mathrm{kPa}$. Begitu pula halnya dengan pengujian pembebanan pondasi dangkal tambahan kolom pada tanah lempung didapatkan grafik hubungan penurunan dan beban (Gambar 6 dan 7). Gambar 6 dan 7 menunjukkan bahwa terjadi penambahan beban yang signifikan terhadap penurunan ketika pondasi diberi perkuatan kolom tanah. 
Beban $(\mathrm{kN})$

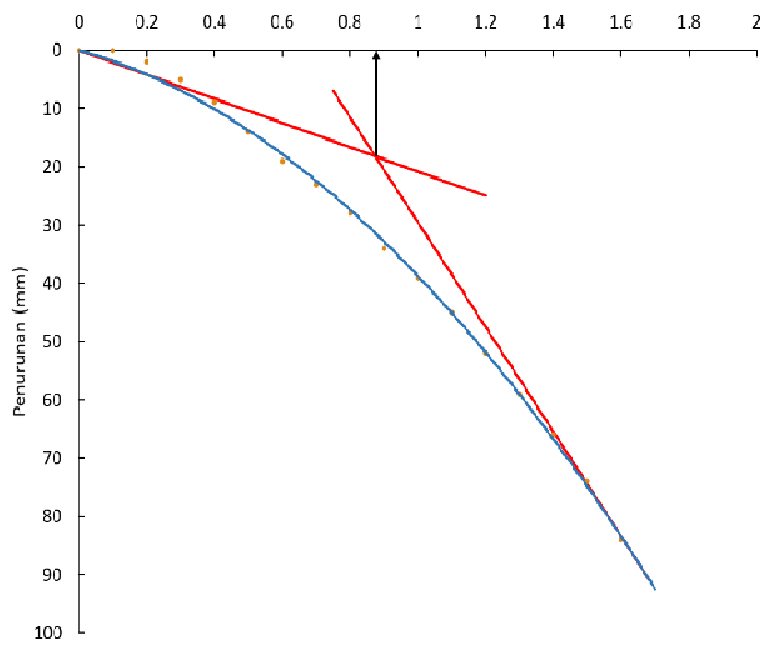

Gambar 5. Grafik hasil pengujian pembebanan untuk pondasi dangkal tanpa perkuatan

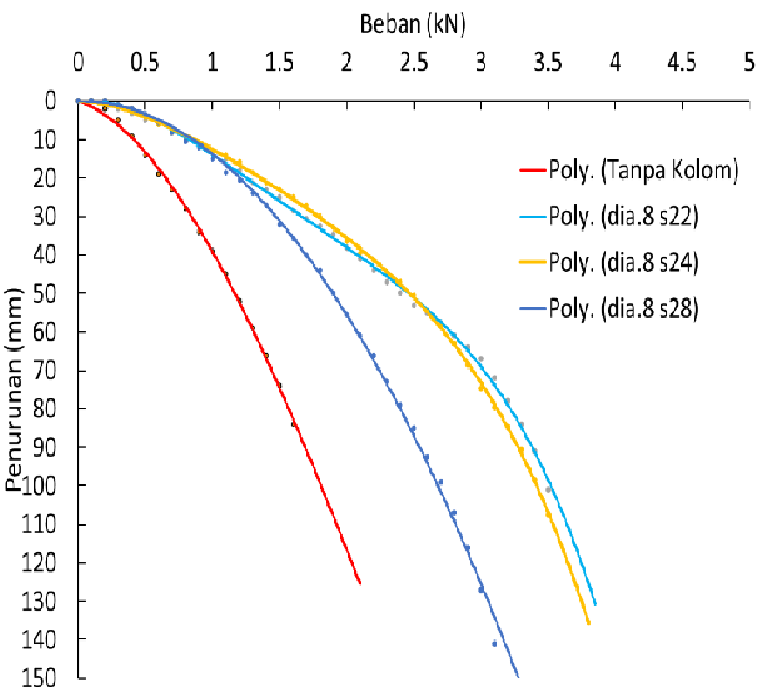

Gambar 6. Grafik hasil pengujian pembebanan untuk variasi jarak antar kolom dengan diameter tetap

Dari Grafik hubungan antara beban dan penurunan, didapat daya dukung pondasi ultimit dengan perkuatan kolom (dengan cara yang sama seperti tanpa perkuatan yaitu dengan metode tangen). Tabel 3 menunjukkan nilai daya dukung pondasi perkuatan kolom untuk setiap variasi.

Daya dukung pondasi (qu) terlihat naik secara signifikan (Tabel 4). Nilai daya dukung tertinggi didapatkan pada variasi diameter kolom $12 \mathrm{~cm}$ dengan jarak antar kolom $30(\mathrm{~s} / \mathrm{d}=2,5)$, yaitu sebesar $39,56 \mathrm{kPa}$.

Jarak antar kolom mempengaruhi nilai daya dukung pondasi, dimana semakin besar jarak antar kolom (s/d naik) daya dukung kelompok kolom menurun. Bertambahnya jarak antar kolom menyebabkan penyebaran beban semakin tidak terpusat sehingga kolom semakin tidak kuat menahan beban yang mengakibatkan penurunan pada nilai daya dukung pondasi. Hasil ini juga berprilaku sama seperti pengujian peningkatan bearing capacity embankment pada tanah loose sandy menggunakan kolom DSM dimana kenaikan rasio s/d dapat menurunkan nilai daya dukung (Esmaeil et al., 2017). Nilai daya dukung kolom kelompok terendah didapatkan pada variasi dengan $\mathrm{s} / \mathrm{d}=3,5$ yaitu sebesar $22 \mathrm{kPa}$ atau $2 \mathrm{x}$ lipat dari nilai daya dukung tanpa perkuatan kolom tanah.

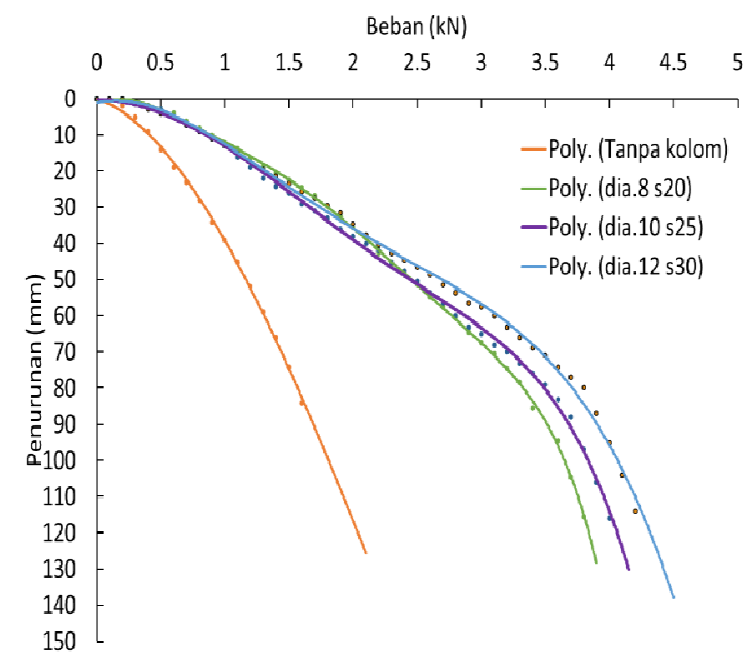

Gambar 7. Grafik hasil pengujian pembebanan untuk variasi diameter kolom dengan s/d sama

Tabel 4. Rekapitulasi nilai qu dengan variasi kolom kelompok

\begin{tabular}{ccccccc}
\hline No & \begin{tabular}{c}
$\mathbf{d}$ \\
\multicolumn{7}{c}{$\mathbf{c m})$}
\end{tabular} & $\begin{array}{c}\mathbf{L} \\
(\mathbf{c m})\end{array}$ & $\begin{array}{c}\mathbf{s} \\
(\mathbf{c m})\end{array}$ & $\begin{array}{c}\text { (s/d) } \\
\text { Tanpa Kolom }\end{array}$ & $\begin{array}{c}\mathbf{P u} \\
\mathbf{k N}\end{array}$ & $\begin{array}{c}\mathbf{q u} \\
\mathbf{k P a}\end{array}$ \\
\hline \multicolumn{7}{c}{ Kolom Kelompok } \\
1 & - & - & - & - & 0,96 & 10,53 \\
\hline & 8 & 67 & 22 & 2,75 & 2,77 & 30,78 \\
3 & 8 & 67 & 24 & 3 & 2,47 & 27,44 \\
4 & 8 & 67 & 28 & 3,5 & 1,98 & 22,00 \\
5 & 8 & 67 & 20 & 2,5 & 2,97 & 33,00 \\
6 & 10 & 67 & 25 & 2,5 & 3,33 & 37,00 \\
7 & 12 & 67 & 30 & 2,5 & 3,56 & 39,56 \\
\hline
\end{tabular}

Diameter kolom kelompok juga mempengaruhi kenaikan nilai daya dukung pondasi tanah lempung, diman semakin bertambahnya diameter kolom kelompok maka nilai daya dukung juga semakin meningkat walaupun jarak antar kolomnya tetap. Perilaku ini juga sama seperti pemodelan kolom DSM berbahan semen menggunakan bantuan software Plaxis 2D, semakin bertambahnya diameter kolom maka nilai faktor keamanan embankment juga semakin meningkat (Esmaeil dkk., 2017). Hal tersebut disebabkan oleh diameter kolom yang bertambah maka luasan area kolom semakin menutupi dasar pondasi yang membuat penyebaran beban semakin terpusat sehingga nilai daya dukung mengalami peningkatan. 
Cantilever $\mid$ Volume: 9 Nomor: 2 Oktober 2020 ISSN: 1907-4247 (Print) $\mid$ ISSN: 2477-4863 (Online) $\mid$ Website: http://cantilever.id Ratna Dewi, dkk. | Peningkatan Daya Dukung Pondasi pada Tanah Lempung dengan Perkuatan Kolom Tanah

\section{Beban Ultimit Kolom Kelompok}

Beban ultimit kolom merupakan nilai pada kolom tanpa adanya tambahan dari tanah sekitarnya. Diameter kolom tanah yang bertambah menyebabkan kontribusi nilai $\mathrm{Pu}$ terhadap daya dukung kelompok kolom menjadi turun (Tabel 5). Hal ini menyebabkan kontribusi kolom pada daya dukung kelompok kolom menjadi bertambah besar. Sebaliknya, semakin jauh jarak antar kolom (dengan diameter dan panjang kolom sama) maka kontribusi kolom pada peningkatan daya dukung semakin turun, sehingga dapat dikatakan penambahan kolom kelompok menjadi tidak berarti.

Tabel 5. Rekapitulasi beban ultimit kolom kelompok

\begin{tabular}{ccccccc}
\hline No & $\begin{array}{c}\mathbf{d} \\
(\mathbf{c m})\end{array}$ & $\begin{array}{c}\mathbf{s} \\
(\mathbf{c m})\end{array}$ & $\begin{array}{c}\mathbf{P u} \\
\mathbf{k N}\end{array}$ & $\begin{array}{c}\mathbf{q u} \\
\mathbf{k P a}\end{array}$ & $\begin{array}{c}\mathbf{P u} \\
\mathbf{k N}\end{array}$ & $\begin{array}{c}\mathbf{P u} \mathbf{g} \\
\mathbf{k N}\end{array}$ \\
\hline 1 & 8 & 22 & 2,77 & 30,78 & 0.743 & 1.957 \\
2 & 8 & 24 & 2,47 & 27,44 & 0.743 & 1.657 \\
3 & 8 & 28 & 1,98 & 22,00 & 0.743 & 1.167 \\
4 & 8 & 20 & 2,97 & 33,00 & 0.743 & 2.157 \\
5 & 10 & 25 & 3,33 & 37,00 & 0.615 & 2.645 \\
6 & 12 & 30 & 3,56 & 39,56 & 0.531 & 2.960 \\
\hline
\end{tabular}

* $\mathrm{Pu}_{1}=$ beban ultimit diluar kolom, $\mathrm{Pu}_{\mathrm{g}}=$ beban ultimit kolom kelompok

\section{Bearing Capacity Ratio (BCR)}

Rasio antara nilai daya dukung pondasi dangkal yang diberi perkuatan kolom dengan daya dukung pondasi tanpa diberi perkuatan disebut dengan Bearing Capacity Ratio (BCR). Nilai BCR diperhitungankan untuk mengetahui besarnya kenaikan daya dukung pondasi berdasarkan variasi dari diameter dan jarak antar kolom tanah. Adapun nilai BCR kolom kelompok untuk setiap variasi disajikan pada Gambar 8.

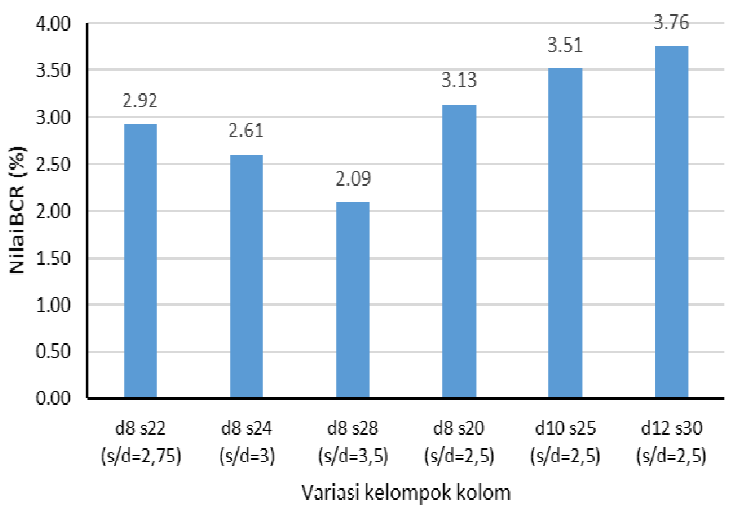

Gambar 8 Nilai BCR setiap variasi kelompok kolom

Dari Gambar 8, terlihat bahwa nilai BCR untuk kolom kelompok tertinggi didapat pada variasi 6, dengan diameter kolom $12 \mathrm{~cm}$ dan jarak antar kolom $30 \mathrm{~cm}(\mathrm{~s} / \mathrm{d}=2,5)$, yaitu sebesar 3,76 dengan persentase kenaikan sebesar 275,69\%. Sedangkan nilai BCR dan persentase kenaikan tekecil untuk kolom kelompok didapat pada variasi dengan diameter $8 \mathrm{~cm}$ dan jarak antar kolom $28 \mathrm{~cm}(\mathrm{~s} / \mathrm{d}=$ $3,5)$, yaitu 2,09 dengan persentase kenaikan $108,93 \%$. Kecenderungan yang sama didapatkan pada penelitian Zaika \& Rachmansyah (2017), dimana terjadi penurunan nilai BCR pada tanah lempung ekspansif terhadap kenaikan besaran s/d.

\section{KESIMPULAN}

Berdasarkan analisis hasil dan pembahasan yang telah dilakukan, dapat ditarik kesimpulan sebagai berikut.

1. Daya dukung pondasi dangkal pada tanah lempung tanpa perkuatan kolom memiliki nilai sebesar $10,53 \mathrm{kPa}$ dan mengalami peningkatan yang cukup signifikan setelah diberi perkuatan kelompok kolom tanah $(2 \times 2)$.

2. Daya dukung pondasi pada tanah lempung setelah diberi perkuatan kolom tanah campuran dengan $6 \%$ abu sekam padi (RHA) menunjukkan peningkatan yang signifikan. Variasi s/d yang meningkat dengan diameter kolom konstan memberikan peningkatan nilai daya dukung menurun. Sedangkan pada variasi diameter yang membesar dengan rasio s/d konstan didapatkan peningkatan daya dukung tanah yang semakin besar.

3. Daya dukung tanah lempung maksimum terjadi pada variasi dengan diameter $12 \mathrm{~cm}$ dan jarak antar kolom $30 \mathrm{~cm}(\mathrm{~s} / \mathrm{d}=2,5)$ dengan nilai qult sebesar 39,56 kPa dan nilai BCR sebesar 3,75\% atau terjadi pengingkatan daya dukung hampir $4 \mathrm{x}$ dari daya dukung tanpa perkuatan.

\section{REFERENSI}

Abdurrozak, M. R. \& Mufti, D. N. (2017). Stabilisasi Tanah Lempung Dengan Bahan Tambah Abu Sekam. Jurnal Teknisia, XXII (2), 416-424.

Basha, A., Sakr, M. A., \& Nimr, A. AL. (2014). An Experimental Study for The Effect of Vacuum Preloading on Soft Soil Improvement. The Eightth Alexandria International Conference On Structural And Geotechnical Engineering (Aicsge8), Alexandria, 14-16 Aptil 2014.

Dehghanbanadaki, A., Ahmad, K., Ali, N., Khari, M., Alimohammadi, P., \& Latifi, N. (2013). Stabilization of Soft Soils with Deep Mixed Soil Columns - General Perspective. Electronic Journal Of Geotechnical Engineering, 18, 295-306.

Dewi, R., Borgan, W., Zunita, I., Yulindasari, \& Iqbal, M. M. (2019). Effect of Deep Soil Mixing to Increasing Bearing Capacity on Peat Soil. International Journal Of GEOMATE, 17(63), 126-132.

Esmaeil, M., Khajehei, H., \& Astaraki, F. (2017). The Effectiveness of Deep Soil Mixing on Enhanced Bearing Capacity and Reduction of Settlement on Loose Sandy Soils. International Journal Of Railway Research, 4(2), 3339.

Estabragh, A. R., Naseh, M., \& Javadi, A. A. (2014). Improvement of Clay Soil by Electro-Osmosis Technique. 
Ratna Dewi, dkk. | Peningkatan Daya Dukung Pondasi pada Tanah Lempung dengan Perkuatan Kolom Tanah

Applied Clay Science, 95, 32-36.

Guetif, Z., Bouassida, M., \& Debats, J. M. (2007). Improved Soft Clay Characteristics due to Stone Column Installation. Computers and Geotechnics, 34(2),104-111.

He, L. \& Liu, H. (2020). Effect Analysis of Different Treatment Methods for Soft Soil Foundation of Highway. Global Journal of Engineering Sciences. https://doi.org/10.33552/GJES.2020.06.000629

Oktavia, D. L., Dewi, R., Saloma, S. Y., Hadinata, F., \& Yulindasari, Y. (2019). The Effects of Rice Husk Ash Substitution on Physical and Mechanical Properties of Clay. International Journal of Scientific and Technology

\section{Research, 8(7), 465-470.}

Puppala, A. J. \& Pedarla, A. (2017). Innovative Ground Improvement Techniques for Expansive Soils. Innov. Infrastruct. Solut. 2, 24. https://doi.org/10.1007/s41062017-0079-2.

Terzaghi, K. \& Ralph, P. B. (1987). Mekanika Tanah dalam Praktek Rekayasa. Jakarta: Penerbit Erlangga.

Zaika, Y. \& Rachmansyah, A. (2017). The Estimation of Bearing Capacity and Swell Potential of Deep Soil Mixing on Expansive Soil by Small Scale Model Test. International Journal of GEOMATE, 13(38), 9-15. 